\title{
Prospective Assessment of the Negative Pressure Wound Therapy of the Open Abdomen.
}

\author{
Martin Hut'an, Christian Bartko, Augustín Prochotský, Jaroslav Sekáč, \\ Ján Škultéty, Juraj Kutarňa, Gerhard Loncsar
}

\section{ORIGINAL RESEARCH}

\begin{abstract}
Open abdomen (OA) is a surgical approach, that emerged in last 15 years, with its management being complicated, timely and financially demanding, burdened with high morbidity and mortality. In recent years, several publications proved superiority of usage of negative pressure wound therapy (NPWT) over usage of conventional temporary abdominal closure techniques in treatment of open abdomen. Different aspects of treatment of OA with NPWT remain to be assessed and stated.

Authors of the paper prospectively assessed group of 48 patients with OA, managed by one surgeon with NPWT between 2006-2014, assessing mortality and morbidity in the group stratified by indication for $\mathrm{OA}$, type of sequential closure of $\mathrm{OA}$, presence and management of concomitant enteroatmospheric fistula (EAF), maximal values of C-reactive protein (CRP) and Procalcitonine (PCT), and initial body mass index (BMI).

Mortality of the whole group was $35.41 \%$, rate of fascial closure $45.83 \%$ and rate of the wound closure $83.33 \%$. Incidence of the fistula was $37.5 \%$, of these $66.67 \%$ were successfully locally managed. Incidence of fascial closure without use of sequential closure was significantly lower as opposed to use of different techniques of sequential closure. Unsuccessful local management of EAF is significant predictor of mortality. All other data were not found to be statistically significant.

Identifying specific aspects of treatment of OA by NPWT, significantly improving outcomes, and adhering to these aspects in clinical practice will further ameliorate outcomes.
\end{abstract}

Keywords-negative pressure wound therapy, open abdomen, temporary abdominal closure

\section{INTRODUCTION}

$\mathbf{O}$ PEN abdomen (OA) technique in the sense of ,temporary abdominal closure“ (TAC) evolved in last 15 years, and found its use in a wide scale of indications encompassing complex abdominal wounds in terms of „damage control surgery“, patients with tertiary peritonitis, abdominal sepsis, and in patients with partial loss of abdominal wall ${ }^{1]}$ Some of the most frequently used conventional techniques of TAC are „Bogota bag“, Witmann patch, Ethizip. In Slovakia, the most commonly used conventional technique for management of OA is „Kern laparostomy“, when OA is covered with moist

Manuscript received 18.03.2016; revised 28.06.2016. This work did not receive any financial support. Authors declare no conflict of interest.

Author affiliations: Surgical department, Landesklinikum Hainburg/Donau, Austria , (MH, JK, GL); 2nd surgical clinic of the Medical faculty, Comenius University, University Hospital Bratislava, Hospital of st. Cyril and Methodius, Bratislava, Slovakia, (CB, AP, JS, JŠ)

*Correspondence to: Martin Hut'an, Surgical department, Landesklinikum Hainburg/Donau, Austria, email: matohuto@yahoo.com gauze and transparent adhesive drape. This technique was published in 1983 as "staged lavage of abdominal cavity“ , introduced by German surgeon Dr. Kern $\cdot^{21}$ Recently published papers showed superiority of NPWT over conventional TAC in patients with $\mathrm{OA} \sqrt[3]{4}$

Because of high variability and relatively small numbers of patients, assessment in terms of evidence based medicine (EBM) is rather uneasy. Pursuit of recommendations based on literary metanalysi ${ }^{5}{ }^{5}$ is complicated and numerous recommendations are of level B, C, and D by SIGN metodology

In our previous paper, we proved statistically significant decrease of mortality by $27.64 \%$ in patient with OA, managed by NPWT vs. conventional TAC (64.71\% vs. $37.04 \%$, $p=0.0256)^{7]}$ and proved statistically significantly higher success of local management of EAF, if NPWT was used. In this paper we compared retrospectively assessed group of patients $(n=17)$ with OA treated by Kern laparostomy, and prospectively assessed group of patients $(n=27)$ treated with NPWT. We continued to prospectively assess patients with OA treated with NPWT and using a ,prospective registry“ we assessed mortality and morbidity in certain aspects of NPWT usage (use of traction mechanism, use of NPWT in patients with EAF) and in relation to BMI on admission and maximum PCT and CRP values. Part of these results can be seen in recommendations, published by Bruhin et al. in 2014 (traction mechanisms, EAF management) and some of them were novel (inflammatory parameters and BMI).

\section{Material And Methods}

From June 2006 till December 2014, 48 patients were prospectively assessed. Inclusion criteria were: management of a patient with open abdomen, age over 18 years. Main exclusion criterion was a known immunodeficiency before the hospitalization. Immunodeficiency was defined as primary immunodeficiency in anamnesis or treatment with immunosuppressive therapy. Patients were hospitalized in IVth Surgical Department of Comenius University, Bratislava (June 2006-January 2009), Clinic of Anesthesiology and Intensive Medicine of Comenius University, Bratislava (June 2006January 2009), 2nd Surgical Department of Comenius University, Bratislava (February 2009 - December 2014), and Anaesthesiological Department of University Hospital Bratislava, hospital of St. Cyril and Methodius, Bratislava (February 2009 
- December 2014). In all patients with open abdomen the redresses were managed and performed by one surgeon.

Indication of OA was:

- decompression of abdominal cavity in presence of ACS by recommendation by WSACS (World Society of Abdominal Compartment Syndrome $)^{\sqrt{8}}$

- 2. Damage control surgery in patient with polytrauma and/or contamination of abdominal cavity

- 3. tertiary peritonitis or presence of surgically technically unsolvable enteral fistula

- 4. dehiscence of laparotomy with infection, necrosis of the part of the fascia or abdominal wall, or inability of closure of abdominal wall

Standard algorithm of the therapy was as follows: all patients received complex intensive therapy aimed at primary disorder, surgical source control of the infection, intensive support therapy in terms of analgesia, circulatory and cardiovascular support, nutritional, renal, metabolic, and immunological support, thromboembolic and gastroduodenal ulcer prevention, and antibiotic therapy. All patients underwent complex laboratory and clinical monitoring daily.

After formation of $\mathrm{OA}$, in all but first four patients commercial kit was used, either KCI ATS (KCI, San Antonio, Tx, USA) or Vivanomed (Paul Hartmann AG, Heidenheim, Germany). In the first four patients we used a „home made“ device, consisting of medicinal polyurethane foam Ligasano (Ligasano GmBH, Cadolzburg, Germany) connected through pressure valve, that was set on $-125 \mathrm{mmHg}$, to central vacuum system in hospital.

Depending on the local status, either no traction mechanisms or compression sutures or their modification were used. Redresses were done every 48-72 hours, in exceptional cases the interval was up to 5 days. Closure of the abdomen at the time of redress was attempted, either in sense of STAR (staged abdominal repair), or as VAFC (vacuum assisted fascial closure) or VAWC (vacuum assisted wound closure). Continuous mode with $-125 \mathrm{mmHg}$ was used in all patients, in patients with EAF was the pressure lowered down to $-75 \mathrm{mmHg}$. Generally, the fist one - two redresses were performed under general anesthesia in operation theatre, the latter redresses in anesthesiological department or intensive care unit under short propofol anesthesia or after pethidin i.m. administration.

In case of presence of the EAF, depending on the local and clinical state of the patient we used one of these approaches:

- creation of proximal stoma with surgical resection and/or closure of the fistula

- attempt of primary closure of the fistula by PVA (polyvinylalcohol) covered with PUR (polyurethan) foam (in case of small fistula, without eversion of mucosa and good nutritional state of the patient)

- diversion of enteral content by Govermann method (in case of surgically unsolvable, large, single fistula) ${ }^{9}$ (diversion of fistula into stoma bag with use of barrier accessories)

- diversion of enteral content by AlKhoury method (in case of surgically unsolvable, multiple fistula) 10 (diversion of fistula by introduction of catheter into fistula opening,
Table I

INDICATION AND USE OF SEQUENTIAL CLOSURE MECHANISM IN OPEN ADOMEN

\begin{tabular}{lccccc}
\hline Indication & $\mathbf{A C S}^{1}$ & $\mathbf{T P}^{2}$ & $\mathbf{D C S}^{3}$ & $\mathbf{D H}^{4}$ & Sum \\
\hline Whole group & 10 & 27 & 5 & 6 & 48 \\
& $(20.83 \%)$ & $(56.25 \%)$ & $(10.42 \%)$ & $(12.5 \%)$ & $(100 \%)$ \\
Use of SCS & 2 & 10 & 2 & 4 & 18 \\
& $(4.16 \%)$ & $(20.83 \%)$ & $(4.16 \%)$ & $(8.33 \%)$ & $(37.5 \%)$ \\
Net use & 1 & 3 & 0 & 1 & 5 \\
& $(2.08 \%)$ & $(6.25 \%)$ & $(0 \%)$ & $(2.08 \%)$ & $(10.42 \%)$ \\
Use of DCS & 2 & 3 & 1 & 0 & 6 \\
No fascia & $(4.16 \%)$ & $(6.25 \%)$ & $(2.08 \%)$ & $(0 \%)$ & $(12.5 \%)$ \\
fixation & $(10.41 \%)$ & $(22.92 \%)$ & $(4.16 \%)$ & $(2.08 \%)$ & $(39.58 \%)$ \\
\hline
\end{tabular}

1 abdominal compartment syndrome,

2 tertiary peritonitis

3 damage control surgery

${ }^{4}$ laparotomy wound dehiscence with fascia necrosis

splint-fixation with NPWT and diversion into collection bag)

- direct application of of PUR over mouth of fistula was attempted only seldom, in case of failure of all previous techniques

In patients with EAF the enteral nutrition was reduced and octreotid $3 \times 0.1 \mathrm{mg}$ s.c. administered, based on patients clinical condition. No enteral treatment by catheter introduction in distal bowel segment was attempted.

Except for basic demographics of the group, following parameters and aspects were prospectively assessed: indication for OA, type of sequential closure mechanism, number of redresses, rate of fascial closure, rate of wound closure, fistula rate, rate of successful primary closure of the fistula, rate of successful diversion of the content of the fistula, initial BMI, maximum CRP and PCT. All parameters were stratified and assessed in terms of mortality.

Patient data were collected in spreadsheet application Microsoft Excel for Mac 2011, (c) 2010 Microsoft Corporation, Redmond, WA, USA. Statistical analysis was performed by Prism 6 for MAC OS X, (c)1994-2014 GraphPad Software, San Diego, CA, USA.

Table II

Relative Use of Sequential Closure Mechanism

\begin{tabular}{lccccc}
\hline Indication & $\mathbf{A C S}^{1}$ & $\mathbf{T P}^{2}$ & $\mathbf{D C S}^{3}$ & $\mathbf{D H}^{4}$ & Sum \\
\hline Use of SCS & 2 & 10 & 2 & 4 & 18 \\
& $(11.11 \%)$ & $(55.55 \%)$ & $(11.11 \%)$ & $(22.22 \%)$ & $(100 \%)$ \\
Net use & 1 & 3 & 0 & 1 & 5 \\
& $(20 \%)$ & $(60 \%)$ & & $(20 \%)$ & $(100 \%)$ \\
Use of DCS & 2 & 3 & 1 & 0 & 6 \\
No fascia & $(33.33 \%)$ & $(50 \%)$ & $(16.67 \%)$ & & $(100 \%)$ \\
fixation & 5 & 11 & 2 & 1 & 19 \\
Whole group & $(26.32 \%)$ & $(57.89 \%)$ & $(10.52 \%)$ & $(5.26 \%)$ & $(100 \%)$ \\
& $(20.83 \%)$ & $(56.25 \%)$ & $(10.42 \%)$ & $(12.5 \%)$ & $(100 \%)$ \\
\hline
\end{tabular}

1 abdominal compartment syndrome,

2 tertiary peritonitis

3 damage control surgery

${ }^{4}$ laparotomy wound dehiscence with fascia necrosis 
Table III

MORTALITY IN GROUP BY INDICATION

\begin{tabular}{lccc}
\hline Indication & $\mathrm{n}$ & Mortality & $\%$ \\
\hline $\mathrm{ACS}^{1}$ & 10 & 4 & $40 \%$ \\
$\mathrm{TP}^{2}$ & 27 & 12 & $44.44 \%$ \\
$\mathrm{DCS}^{3}$ & 5 & 1 & $20 \%$ \\
$\mathrm{DH}^{4}$ & 6 & 0 & $0 \%$ \\
$\mathrm{Sum}$ & 48 & 17 & $35.41 \%$ \\
\hline
\end{tabular}

$\mathrm{p}=0.1838$ (Log-rank, Mantel - Cox test)

1 abdominal compartment syndrome,

2 tertiary peritonitis

3 damage control surgery

${ }^{4}$ laparotomy wound dehiscence with fascia necrosis

Table IV

Mortality in Group by Sequential Closure Mechanism

\begin{tabular}{lccc}
\hline Fixation & $\mathrm{n}$ & Mortality & $\%$ \\
\hline No fixation & 19 & 9 & $47.36 \%$ \\
$\mathrm{Net}^{3}$ & 5 & 2 & $40 \%$ \\
$\mathrm{SCS}^{1}$ & 18 & 4 & $22.22 \%$ \\
$\mathrm{DCS}^{2}$ & 6 & 2 & $33.33 \%$ \\
Sum & 48 & 17 & $35.41 \%$ \\
\hline 1 & static compression sutures \\
2 & dynamic compression sutures \\
3 & \\
\multicolumn{4}{l}{ net traction or SMAC modification (sand- } \\
wich abdominal closure)
\end{tabular}

\section{RESULTS}

48 patients with the average age of 56.45 years were prospectively assessed (25 males (52.08\%), average age 55.92; 23 females $(47.92 \%)$, average age 57.04 years.) The average number of redresses was 5.66 (range: 1-12). Techniques of fixation in different indications are listed in Table \ and II

Mortality in the group based on indications are shown in Table III. and based on the type of fixation in Table IV Overall mortality in the whole group was $35.41 \%$. Analysis of closure of the fascia and closure of the wound stratified by indication for OA is stated in Table $\mathrm{V}$ Assessment of the closure of the fascia and closure of the wound stratified by the type of fixation is stated in Table VI

Assessment of the presence of the fistula, successful closure

Table V

Closure of the Fascia and Closure of the Wound Stratified by INDICATION FOR OA

\begin{tabular}{lcllcccr}
\hline Indication & $n$ & Fascia & \multicolumn{4}{c}{ Wound closure } \\
& & closure (\%) & $\mathrm{A}^{5}$ & $\mathrm{~B}^{6}$ & $\mathrm{C}^{7}$ & $\mathrm{D}^{8}$ & Sum (\%) \\
\hline $\mathrm{ACS}^{1}$ & 10 & $3(30 \%)$ & 0 & 1 & 3 & 5 & $990 \%$ \\
$\mathrm{TP}^{2}$ & 27 & $12(44.44 \%)$ & 0 & 1 & 17 & 3 & $2177.78 \%$ \\
$\mathrm{DCS}^{3}$ & 5 & $2(40 \%)$ & 1 & 0 & 2 & 1 & $480 \%$ \\
$\mathrm{DH}^{4}$ & 6 & $5(83.33 \%)$ & 0 & 2 & 3 & 1 & $480 \%$ \\
$\mathrm{Sum}$ & 48 & $22(45.83 \%)$ & 1 & 4 & 25 & 10 & $4083.33 \%$ \\
\hline
\end{tabular}

$\mathrm{p}=0.2210$ for fascia closure (Gehan-Breslow-Wilcoxon test)

$p=0.2651$ for overall wound closure (Gehan-Breslow-Wilcoxon test)

1 abdominal compartment syndrome,

2 tertiary peritonitis

3 damage control surgery

${ }^{4}$ laparotomy wound dehiscence with fascia necrosis

5 Wound closure in 7 days

${ }^{6}$ Wound closure in 10 days

7 Wound closure in 30 days

${ }^{8}$ Over 30 days after the end of hospitalization
Table VI

TYPE OF FIXATION

\begin{tabular}{lclllllr}
\hline Indication & $n$ & $\begin{array}{l}\text { Fascia } \\
\text { closure (\%) }\end{array}$ & $\mathrm{A}^{4}$ & $\mathrm{~B}^{5}$ & $\mathrm{C}^{6}$ & $\mathrm{D}^{7}$ & Sum (\%) \\
\hline No fixation & 19 & $1(5.26 \%)$ & 0 & 0 & 12 & 5 & $17(89.47 \%)$ \\
$\mathrm{Net}^{1}$ & 5 & $5(100 \%)$ & 0 & 0 & 3 & 2 & $5(100 \%)$ \\
$\mathrm{SCS}^{2}$ & 18 & $12(66.67 \%)$ & 0 & 3 & 9 & 2 & $14(77.78 \%)$ \\
$\mathrm{DCS}^{3}$ & 6 & $4(66.67 \%)$ & 1 & 1 & 1 & 1 & $4(66.67 \%)$ \\
Sum & 48 & $21(43.75 \%)$ & 1 & 4 & 25 & 10 & $40(83.33 \%)$ \\
\hline
\end{tabular}

$\mathrm{p}<0.0001$ for fascia closure (Gehan-Breslow-Wilcoxon test)

$\mathrm{p}=0.9734$ for overall wound closure (Gehan-Breslow-Wilcoxon test)

1 static compression sutures

2 dynamic compression sutures

${ }^{3}$ net traction or SMAC modification (sandwich mesh abdominal closure)

${ }^{4}$ Wound closure in 7 days

5 Wound closure in 10 days

6 Wound closure in 30 days

${ }^{7}$ Over 30 days after the end of hospitalization

Table VII

Assessment of the Presence of the Fistula, Successful Closure of the Fistula, SucCessful Diversion of the Fistula, AND THEIR STRATIFICATION BASED ON THE INDICATION

\begin{tabular}{lcccc}
\hline Indication & $\mathbf{A}^{5}(\%)$ & $\mathbf{B}^{6}(\%)$ & $\mathbf{C}^{7}(\%)$ & $\mathbf{D}^{8}(\%)$ \\
\hline $\mathrm{ACS}^{1}$ & $3(30 \%)$ & 0 & $2(66.67 \%)$ & $1(33.33 \%)$ \\
$\mathrm{TP}^{2}$ & $14(51.85 \%)$ & $5(35.71 \%)$ & $4(28.57 \%)$ & $5(35.71 \%)$ \\
$\mathrm{DCS}^{3}$ & $1(20 \%)$ & 0 & $1(100 \%)$ & 0 \\
$\mathrm{DH}^{4}$ & 0 & 0 & 0 & 0 \\
Sum & $18(37.5 \%)$ & $5(27.78 \%)$ & $7(38.89 \%)$ & $6(33.33 \%)$ \\
\hline
\end{tabular}

abdominal compartment syndrome,

2 tertiary peritonitis

3 damage control surgery

${ }^{4}$ laparotomy wound dehiscence with fascia necrosis

${ }^{5}$ fistula present

${ }^{6}$ successful closure of the fistula (primary or resection)

7 successful diversion of the fistula content

${ }^{8}$ unsuccessful diversion of the fistula content

of the fistula, successful diversion of the fistula, and their stratification based on the indication is shown in the Table VII. Mortality rate of the patients with fistulas is shown in the Table VIII. Maximal values of CRP, PCT, initial BMI in relation to mortality is shown in the Table IX

\section{Discussion}

Use of NPWT in patients with OA showed its superiority over conventional techniques of temporary abdominal closure in a number of studies 3 This paper is an extension of prospectively assessed group of patients, started in our paper, that similarly showed lowering of mortality and morbidity in patients, where NPWT was used for treatment of $\mathrm{OA}^{[7}$ In this paper we assessed prospectively 27 patients, after continuation

Table VIII

Mortality Rate of Patients with Fistula in OA

\begin{tabular}{lllll}
\hline & $\mathbf{n}$ & $\%$ & mortality & \% \\
\hline $\mathrm{B}^{2}$ & 5 & $27.78 \%$ & 1 & $20 \%$ \\
$\mathrm{C}^{3}$ & 7 & $38.89 \%$ & 2 & $28.57 \%$ \\
$\mathrm{D}^{4}$ & 6 & $33.33 \%$ & 5 & $83.33 \%$ \\
$\mathrm{~A}^{1}=\mathrm{B}+\mathrm{C}+\mathrm{D}$ & 18 & $100 \%$ & 8 & $44.44 \%$ \\
\hline${ }^{1}$ fistula present \\
${ }^{2}$ successful closure of the fistula (primary or resection) \\
${ }^{3}$ successful diversion of the fistula content \\
${ }^{4}$ unsuccessful diversion of the fistula content
\end{tabular}


Table IX

Maximal Values of CRP, PCT and Initial Values of BMI in CONTEXT With MORTALITY RATE

\begin{tabular}{llll}
\hline & $\mathrm{A}^{1}\left(\mathrm{SEM}^{3}\right)$ & $\mathrm{B}^{2}\left(\mathrm{SEM}^{3}\right)$ & $\mathrm{p}$ \\
\hline$n$ & 31 & 17 & \\
CRP $(\mathrm{mg} / \mathrm{l})$ & $238.9(24.97)$ & $194.9(15.77)$ & 0.1256 \\
PCT (ng/ml) & $10.15(4.974)$ & $5.39(0.7861)$ & 0.2698 \\
BMI (kg/m2) & $25.36(0.9218)$ & $30.14(2.388)$ & 0.1673 \\
\hline
\end{tabular}

$\mathrm{p}$ counted as unpaired double tailed t-test

1 non survivors

survivors

${ }^{3}$ SEM - standard error of the mean given in the brackets

of assessment we added another 21 patients, while assessing different aspects of the treatment of OA with NPWT.

No matter what type of sequential mechanism for closure of OA is used, whether these are dynamic compression sutures (DCS), static compression sutures (SCS), polypropylene meshes in terms of SMAC - sandwich mesh abdominal closure, ${ }^{10}$ or commercially made systems (ABRA system, Canica Medical Products Inc., Ontario, Canada), they showed significantly higher ratio of possible fascia closure in patients with OA. $11+19$

In our group the most commonly used fixation were static sutures $(37.5 \%)$, in $39.5 \%$ of patients no fixation was used. If considering relative numbers, more than half of the patients with ACS (26\% of all patients) had no fixation. Same relative ratio of use of SCS and no fixation (approximately $40 \%$ to $40 \%$ ) was used in patients with tertiary peritonitis and in patients treated by damage control surgery. In patients with dehiscence of laparotomy, use of SCS (66\%) highly exceeds other choices of fixation.

Overall wound closure rate is $83.33 \%$ and neither indication nor method of fixation had significant impact on the change. Vacuum assisted fascial closure is significantly lower in patients, where no fixation was used $(5.25 \%)$ as opposed to those, where we used one of the types of fixation $(66.67 \%-100 \%$. $\mathrm{p}<0.0001)$. We found out in our patients, that centripetal power of closure of wound with NPWT is not sufficient enough to counter retraction of the fascia and ensure closure of the fascia in other circumstance, than by surgical deliberation (such as component separation technique). In the presence of longer lasting treatment, such operation is technically difficult, if not impossible to perform. In patients, where fixation mechanism for prevention of fascial retraction were used, we see significantly higher rates of possible fascial closure by ensuring relative proximity of fascial edges.

Enteroatmospheric fistula is considered the most devastating complication of $\mathrm{OA}, 20$ with incidence ranging from $5 \%$ to $75 \%$. 21.23 As more than $90 \%$ of fistulas are of iatrogenic origin, with their increasing incidence rate hand in hand with the prolongation of definite closure of $\mathrm{OA}, \sqrt{21}-23$ the closure of OA should be performed as soon as possible. Even though there are debates over increased fistula rates in patient with OA managed by NPWT, 24 our latest paper did not support this opinion. ${ }^{7} 18$ patients $(37.5 \%)$ developed enteroatmospheric fistula. In 5 patients $(27.78 \%$ ) closure of the fistula (primary or by resection) was successful, in other 7 patients $(38.89 \%)$ fistulas were successfully managed by enteral content diversion either by Goverman or AlKhoury method. In one third of the patients with fistula (33.33\%, 6 patients), we were unable to control the enteral content. While sum mortality for patients with developed fistula were $44.44 \%$, in patients, where we could perform closure or diversion of the fistula, mortality rate was $20 \%$ and $28.57 \%$. Patients with untreatable enteroatmospheric fistula reached mortality rate of $83.33 \%$, stating statistically significant $(p=0.0356)$ inability to treat fistula as a predictor of mortality in patients with OA.

Two group of patients (survivors, non-survivors) were stratified with BMI (Body Mass Index), maximum CRP (C reactive protein) and PCT (Procalcitonine). No statistically significant data could be identified stating, that neither BMI, nor maximum CRP or PCT can be identified as a mortality predictor in patients with $\mathrm{OA}$.

\section{CONCLUSION}

Use of NPWT in patients with OA has shown to be a golden standard in management of patients with OA. Use of NPWT significantly lowers morbidity and mortality in patients with OA. Use of sequential closure mechanisms of abdominal wall significantly increases rate of fascia closure, having impact on aesthetic and functional properties of abdominal wall ad should be a gold standard in management of patients with OA with NPWT. Management of enteroatmospheric fistulas with NPWT remains one of the few effective possibilities of diversion of enteral content, which, when not diverted, is proved to be a predictor of mortality. Temporary abdominal closure should be performed as soon as possible to avoid complications of OA (fistula, fascia retraction).

Although NPWT brought many positive improvements to patients with OA, it remains a new, rapidly developing method, which has to be viewed as a complementary method in surgical wound management.

\section{REFERENCES}

[1] D. J. Worhunsky, G. Magee, and D. A. Spain, "Challenges in the management of the open abdomen," ICU Director, dec 2012. [Online]. Available: http://dx.doi.org/10.1177/1944451612469628

[2] E. Kern, P. Klaue, and R. Arbogast, "Programmierte peritoneal-lavage bei diffuser peritontis," Chirurg, vol. 54, pp. 306-310, 1983.

[3] A. J. Quyn, C. Johnston, D. Hall, A. Chambers, N. Arapova, S. Ogston and A. I. Amin, "The open abdomen and temporary abdominal closure systems - historical evolution and systematic review," Colorectal Disease, vol. 14, no. 8, pp. e429-e438, jul 2012. [Online]. Available: http://dx.doi.org/10.1111/j.1463-1318.2012.03045.x

[4] D. J. Roberts, D. A. Zygun, J. Grendar, C. G. Ball, H. L. Robertson, J.-F. Ouellet, M. L. Cheatham, and A. W. Kirkpatrick, "Negative-pressure wound therapy for critically ill adults with open abdominal wounds," Journal of Trauma and Acute Care Surgery, vol. 73, no. 3, pp. 629-639, sep 2012. [Online]. Available: http://dx.doi.org/10.1097/TA.0b013e31825c130e

[5] A. Bruhin, F. Ferreira, M. Chariker, J. Smith, and N. Runkel, "Systematic review and evidence based recommendations for the use of negative pressure wound therapy in the open abdomen," International Journal of Surgery, vol. 12, no. 10, pp. 1105-1114, oct 2014. [Online]. Available: http://dx.doi.org/10.1016/j.ijsu.2014.08.396

[6] Scottish Intercollegiate Guidelines Network (SIGN), SIGN 50: a guideline developer's handbook. Edinburgh: SIGN: (SIGN publication no. 50), 2015. [Online]. Available: http://www.sign.ac.uk

[7] J. Hutan, M. Hutan, J. Skultety, J. Sekac, P. Koudelka, A. Prochotsky, A. Yaghi, and P. Labas, "Use of intraabdominal vac (vacuum assisted closure) lowers mortality and morbidity in patients with open abdomen." Bratislavske lekarske listy, vol. 114, no. 8, pp. 451-454, 2012. 
[8] A. W. Kirkpatrick, D. J. Roberts, J. D. Waele, R. Jaeschke, M. L. N. G. Malbrain, B. D. Keulenaer, J. Duchesne, M. Bjorck, A. Leppaniemi, J. C. Ejike, M. Sugrue, M. Cheatham, R. Ivatury, C. G. Ball, A. R. Blaser, A. Regli, Z. J. Balogh, S. D’Amours, D. Debergh, M. Kaplan, E. Kimball, and C. Olvera, "Intra-abdominal hypertension and the abdominal compartment syndrome: updated consensus definitions and clinical practice guidelines from the world society of the abdominal compartment syndrome," Intensive Care Med, vol. 39, no. 7, pp. 1190-1206, may 2013. [Online]. Available: http://dx.doi.org/10.1007/s00134-013-2906-z

[9] J. Goverman, J. A. Yelon, J. J. Platz, R. C. Singson, and M. Turcinovic, "The "fistula VAC", a technique for management of enterocutaneous fistulae arising within the open abdomen: Report of 5 cases," The Journal of Trauma: Injury, Infection, and Critical Care, vol. 60, no. 2, pp. 428-431, feb 2006. [Online]. Available: http://dx.doi.org/10.1097/01.ta.0000203588.66012.c4

[10] M. Hutan Jr and M. Hutan Sr, "Sandwich mesh abdominal closure," Bratisl Lek Listy, vol. 111, no. 8, pp. 461-463, 2010.

[11] C. C. Burlew, E. E. Moore, W. L. Biffl, D. D. Bensard, J. L. Johnson, and C. C. Barnett, "One hundred percent fascial approximation can be achieved in the postinjury open abdomen with a sequential closure protocol," Journal of Trauma and Acute Care Surgery, vol. 72, no. 1, pp. 235-241, jan 2012. [Online]. Available: http://dx.doi.org/10.1097/TA.0b013e318236b319

[12] R. Kafka-Ritsch, M. Zitt, N. Schorn, S. Stroemmer, S. Schneeberger, J. Pratschke, and A. Perathoner, "Open abdomen treatment with dynamic sutures and topical negative pressure resulting in a high primary fascia closure rate," World J Surg, vol. 36, no. 8, pp. 1765-1771, apr 2012. [Online]. Available: http://dx.doi.org/10.1007/s00268-012-1586-0

[13] K. Sörelius, A. Wanhainen, S. Acosta, M. Svensson, K. DjavaniGidlund, and M. Björck, "Open abdomen treatment after aortic aneurysm repair with vacuum-assisted wound closure and meshmediated fascial traction," European Journal of Vascular and Endovascular Surgery, vol. 45, no. 6, pp. 588-594, jun 2013. [Online]. Available: http://dx.doi.org/10.1016/j.ejvs.2013.01.041

[14] S. Acosta, T. Bjarnason, U. Petersson, B. Pålsson, A. Wanhainen, M. Svensson, K. Djavani, and M. Björck, "Multicentre prospective study of fascial closure rate after open abdomen with vacuum and mesh-mediated fascial traction," British Journal of Surgery, vol. 98, no. 5, pp. 735-743, jan 2011. [Online]. Available: http://dx.doi.org/10.1002/bjs.7383

[15] U. Petersson, S. Acosta, and M. Björck, "Vacuum-assisted wound closure and mesh-mediated fascial traction-a novel technique for late closure of the open abdomen," World J Surg, vol. 31, no. 11, pp. 2133-2137, sep 2007. [Online]. Available: http: //dx.doi.org/10.1007/s00268-007-9222-0

[16] S. K. Rasilainen, P. J. Mentula, and A. K. Leppäniemi, "Vacuum and mesh-mediated fascial traction for primary closure of the open abdomen in critically ill surgical patients," British Journal of Surgery, vol. 99, no. 12, pp. 1725-1732, oct 2012. [Online]. Available: http://dx.doi.org/10.1002/bjs.8914

[17] J. Kleif, R. Fabricius, C. A. Bertelsen, J. Bruun, and I. Gögenur, "Promising results after vacuum-assisted wound closure and meshmediated fascial traction," Dan med J, vol. 59, no. 9, p. A4495, 2012.

[18] A. E. Salman, F. Yetişir, M. Aksoy, M. Tokaç, M. B. Yildirim, and M. Kiliç, "Use of dynamic wound closure system in conjunction with vacuum-assisted closure therapy in delayed closure of open abdomen," Hernia, vol. 18, no. 1, pp. 99-104, oct 2012. [Online]. Available: http://dx.doi.org/10.1007/s10029-012-1008-0

[19] F. J. Verdam, D. E. J. G. J. Dolmans, M. J. Loos, M. H. Raber, R. J de Wit, J. A. Charbon, and J. P. A. M. Vroemen, "Delayed primary closure of the septic open abdomen with a dynamic closure system," World J Surg, vol. 35, no. 10, pp. 2348-2355, aug 2011. [Online]. Available: http://dx.doi.org/10.1007/s00268-011-1210-8

[20] W. SCHECTER, R. IVATURY, M. ROTONDO, and A. HIRSHBERG, "Open abdomen after trauma and abdominal sepsis: A strategy for management," Journal of the American College of Surgeons, vol. 203, no. 3, pp. 390-396, sep 2006. [Online]. Available: http://dx.doi.org/10.1016/j.jamcollsurg.2006.06.001

[21] A. EVENSON and J. FISCHER, "Current management of enterocutaneous fistula," Journal of Gastrointestinal Surgery, vol. 10, no. 3, pp. 455-464, $\operatorname{mar} 2006$. [Online]. Available: http://dx.doi.org/10.1016/j.gassur.2005.08.001

[22] A. de Costa, "Making a virtue of necessity: managing the open abdomen," ANZ J Surg, vol. 76, no. 5, pp. 356-363, may 2006. [Online]. Available: http://dx.doi.org/10.1111/j.1445-2197.2006.03638.x

[23] A. Schachtrupp, V. Fackeldey, U. Klinge, J. Hoer, A. Tittel, C. Toens, and V. Schumpelick, "Temporary closure of the abdominal wall (laparostomy)," Hernia, vol. 6, no. 4, pp. 155-162, dec 2002. [Online]. Available: http://dx.doi.org/10.1007/s10029-002-0085-x

[24] I. A. Shaikh, A. Ballard-Wilson, S. Yalamarthi, and A. I. Amin, "Use of topical negative pressure in assisted abdominal closure does not lead to high incidence of enteric fistulae," Colorectal Disease, vol. 12, no. 9, pp. 931-934, apr 2009. [Online]. Available: http://dx.doi.org/10.1111/j.1463-1318.2009.01929.x 